I Left Venus and Came Back to Mars: Temporal Focus Congruence in Dyadic Relationships following Maternity Leave

Yseult Freeney ${ }^{1}$, Lisa van der Werff ${ }^{1}$ and David G. Collings ${ }^{1}$

${ }^{1}$ DCU Business School

Dublin City University

To cite this article: Yseult Freeney, Lisa van der Werff, David G. Collings (2021) I Left Venus and Came Back to Mars: Temporal Focus Congruence in Dyadic Relationships Following Maternity Leave.

https://doi.org/10.1287/orsc.2021.1508

Published online in Articles in Advance 03 Dec 2021. 


\title{
I Left Venus and Came Back to Mars: Temporal Focus Congruence in Dyadic Relationships following Maternity Leave
}

\begin{abstract}
Temporal focus on past, present and future of contributions to work is critical to understanding how employees and their line managers navigate career disruptions and minimise their potential for negative impact. This paper reframes temporal focus using a dyadic, relational perspective to explore how temporal focus (in)congruence shapes resocialization experiences for returners and their line managers following maternity leave disruption. Our qualitative study draws on 54 interviews across 27 organizations and demonstrates that a congruent, broader temporal focus - that embraces the past, present and the future - is associated with more positive relational and career outcomes than an incongruent focus, where one dyadic partner holds a narrow temporal focus. Our findings explicate how the adoption of a broad versus narrow temporal focus creates a perception of maternity leave as either a brief interlude or a major disruption. A congruent, broader temporal focus allows returners and their line managers to reduce their reliance on typical motherhood biases and instead consider the woman's past, present and potential future contributions over the course of her career. We highlight the importance of temporal focus congruence at a dyadic level and the value of adopting a broader temporal focus on careers, while offering new insights regarding the temporal dynamics inherent to maternity leave transitions for both returners and their managers.
\end{abstract}

Keywords: Temporal Focus; Congruence; Maternity Leave; Motherhood Bias 


\section{Introduction}

Organizations increasingly rely on the temporal coordination of employee effort to function effectively and employee orientations towards time are recognized as important drivers of organizational outcomes (Shipp and Richardson 2020). Temporal focus refers to the extent to which individuals typically orient their attention to information pertaining to the past, present or future (Shipp, Edwards and Lambert 2009). The perception and salience of past, present and future experiences have been demonstrated to impact a range of variables relevant to careers, from risk taking to professional achievement (Levasseur, Shipp, Fried, Rousseau and Zimbardo 2020). A growing body of evidence indicates that a strong focus on any one temporal focus has important implications including for wellbeing and career progress (see Shipp, in press for a review). Although the literature on temporal focus typically evokes the concept as a type of individual difference, there is increasing awareness of the potential for state or event specific elements of temporal focus (e.g. Cojuharenco, Patient and Bahshur, 2011) that may enhance its importance at particular career stages.

While the importance of temporal focus at the individual level has been established, the temporal focus of influential others at work is also likely to have a considerable impact. Few workers operate in isolation of others and most depend heavily on relationships with their managers and colleagues. Time is experienced in organizations through shared temporal structures and norms which synchronize and create a rhythm to working life and longer-term careers (Ancona and Chong 1996, Orlikowski and Yates 2002). In a work relationship, a dyadic partner or colleague may act as an important 'yardstick' for aligning with workplace temporal norms. Although relational perspectives on temporal focus within workplaces are somewhat understudied, the important role that temporal focus can play in interpersonal interpretations of behavior has been considered from a theoretical perspective (Cole, Shipp and Taylor 2016). We expect interpersonal aspects of temporal focus to be particularly salient in contexts where the temporal rhythm of the workplace, career, or work relationship is disrupted, creating room for differing temporal perspectives to develop. As such, understanding the processes underlying matches or mismatches of temporal orientations between 
employees and colleagues such as line managers during organizational or relational disruption is critical to navigating this disruption and minimizing potential for negative impact on individual careers.

Our qualitative research set out to understand how women navigate the disruption of work and career on their return to work after the interruption of maternity leave. In this paper, we take an abductive approach to analyzing the returner-line manager dyad as a way of understanding how (in)congruence in temporal foci can impact on how returners and their managers view maternity leave within the broader context of the returners' careers. Pregnancy and the ensuing maternity leave represent a challenging punctuation in a woman's career that requires considerable effort in maintaining a professional image (Little, Major, Hinojosa and Nelson 2015). Despite such endeavors, women often find that their position within the organization is 'unfavorably revised' during pregnancy and following maternity leave (Gatrell 2013). Women who return to work following maternity leave, or returners, often grapple with motherhood biases that lead to unfavorable judgements of them as workers and have adverse consequences for their careers (Correll, Benard and Paik 2007, Heilman and Okimoto, 2008). While such bias has mostly been studied at the point of hire (Gough and Noona 2013), it may be more pronounced for returners due to disruptions to their visibility, professional identity and workplace relationships. Given the temporal disruption that is inherent in maternity leave, it presents a salient context in which to explore temporal focus at a relational level.

Our research represents an important first step in explicating how the (in)congruence in temporal focus of dyadic partners shapes resocialization outcomes following a career interruption. Our research makes two critical contributions to the literature on temporal focus. First, while state and trait perspectives on temporal focus and closely related concepts have highlighted important outcomes at the individual level, relational perspectives on temporal focus are sparse (Shipp and Aeon 2019). We demonstrate the importance of an individual's temporal focus relative to the temporal focus of important dyadic partners (line managers) and the potential for this to impact resocialization outcomes. In particular, our data illustrate the potential for (in)congruence in temporal focus to impact relational and career related outcomes and contributes to our nascent understanding of 
temporal focus fit (Briker, Walter and Cole 2020; Waller, Franklin and Parcher 2020). Second, building on recent work on the variant outcomes of past, present and future temporal foci (e.g. Shipp in press), we demonstrate the differential impact of a present focus on maternity leave versus a broader, more holistic focus. The negative outcomes associated with a past focus have been highlighted previously, while present and future foci are positioned as a mixed blessing (Levasseur et al. 2020). Our data suggest that, rather than one particular focus being more advantageous than another, a broader temporal focus allows returners and their managers to consider past investment and potential future contribution alongside the more immediate experiences of the return to work after maternity leave.

Finally, we contribute to the growing literature on resocialization through a dyadic perspective on the return to work post maternity leave. Our research moves this literature beyond individual identity shifts (Hennekam, Syed, Ali and Dumazert 2019, Hennekam 2016, Ladge and Greenberg 2015) to highlight the central role of (in)congruence in temporal focus and relationships during this transitional process. Specifically, we explicate how individual and dyadic temporal foci on maternity leave - as a brief interruption or major temporal disruption - shape experiences and outcomes during resocialization. We highlight the differential impact of relationships where that temporal focus is broad or narrow and the extent to which that focus is shared within dyads. Importantly, our findings illustrate how a broader temporal focus can reduce reliance on the motherhood bias by facilitating a more holistic and systematic consideration of past, present and future contributions. In contrast, a narrower focus, particularly where only present contribution and availability were salient, resulted in an increased reliance on the motherhood bias during this time and more negative resocialization outcomes. These insights position broad, congruent temporal focus as a key, not only to mitigating the potential negative impacts of maternity leave, but to unlocking the potential of this transition to strengthen women's careers and workplace relationships.

\section{Theoretical Background}

\section{Temporal Focus in Workplace Relationships}


Temporal focus provides a useful lens for understanding how individuals think about the past, present, and future (Levasseur et al. 2020; Schipp et al. 2009). It highlights the subjective perspective of time, and how it acts as a significant influence on a vast array of organizational outcomes (Shipp and Richardson 2020). In general, past temporal focus is associated with more maladaptive outcomes, such as lower well-being and negative affect (Shipp et al. 2009; Rush and Grouzet 2012). In contrast, future temporal focus is argued to be associated with achievement (Shipp and Aeon 2019) and career adaptability (Zacher 2014); while present focus is viewed as something of a double-edged sword. There is also increasing recognition of the advantages of balancing multiple temporal foci, rather than individuals having a singular focus on past, present or future (Waller et al. 2020). As our understanding of temporal focus develops, the significance of state or situational influences and the need to understand the social context of temporal focus has also been highlighted (Levasseur et al., 2020).

Although relational perspectives on temporal perspectives within workplaces are understudied, theoretical insights suggest that temporal focus can play an important role in interpersonal interpretations of workplace behavior (Cole, Shipp and Taylor 2016). Temporal focus impacts behaviors (Leroy, Shipp, Blount and Licht 2015; Shipp and Aeon 2019), and may have an impact on salient others, for instance, through citizenship behaviors (Methot, Lepak, Shipp and Boswell 2017). Furthermore, temporal aspects of team members' personalities may shape managers' evaluations of subordinates (Alipour, Mohammed and Martinez 2017). Moving beyond individual temporal foci, we argue that any mismatches in subjective views of time within teams, or between managers and their teams, may illicit negative reactions that can significantly impact on work outcomes (Briker et al. 2020, Eldor et al. 2017). Recent evidence (Briker et al., 2020; Waller et al., 2020) suggests that incongruence in temporal focus may be relatively common and points to the need to examine the role of perceived incongruence or misfit in inhibiting team functioning.

Traditionally, temporal focus, even that at a relational level, has largely been positioned as a trait or dispositional variable (Ancona, Okhuysen and Perlow, 2001, Shipp et al. 2009, Zimbardo and Boyd 2008). However, we argue that it can fluctuate in response to life events (see also Holman \& 
Silver 2005) or situational cues, where sporadic events can present threats or opportunities, resulting in a shift in time perspective (Levasseur et al. 2020). This potential for change in temporal focus over time highlights the possibility of in(congruence) in temporal focus in the workplace, and further that this congruence is not likely to be static. In particular, we expect such temporal disruptions within workplace relationships, where normal temporal rhythms are interrupted due to temporary absence, to be influential both in making temporal focus more salient and in creating opportunities for (in)congruence to develop.

Our understanding of the disruption of temporal norms in relationships and the extent to which such disruption may impact on the relationship itself or career outcomes for employees is, however, limited. There are two stark oversights in the literature in this regard. First, despite temporal disruption being a common experience for many workers (e.g. maternity/parental leave, sabbaticals, boomerang hires, long term sick leave), research that considers how people respond to disruption, fails to adopt a temporal lens to understand the adjustments required. Rather, extant research has focused on how individuals engage in identity negotiation and sensemaking to adjust (Ladge, Humberd and Eddleston 2018, Ladge and Greenberg 2015), or focuses on performance outcomes (Keller, Kehoe, Bidwell, Collings and Myer 2020, Swider, Liu, Harris and Gardner 2017). This approach overlooks the fact that, due to the passage of time, temporal processes are likely to be influential following a significant absence. Second, extant research largely ignores the relational dimension of social norms - that is, it takes more than one person to generate a (temporal) norm. In the context of disruption, where one member is detached from those norms, workplace relationships may be themselves impacted. Progress in recognizing the importance of shared or divergent temporal orientations (e.g. Alipour et al. 2017) has not been considered in the context of temporal disruption. We argue that interruptions to temporal rhythms may disrupt relationships and stimulate re-evaluations during which time temporal focus incongruence may be more likely to occur and become salient to relational partners. 
Our focus is on how temporal disruptions and incongruence in temporal foci influence career and relational outcomes, in the context of the return to work after maternity leave, integrating theory from the literature on motherhood biases (Glass and Fodor 2018, Benard and Correll 2010) and the return to work after leave (Ladge and Greenberg 2015). Maternity leave is a very common career interruption and is a very particular time at which parenthood directly impacts on a woman's availability for and visibility at work in particular (McDonald, Bradley and Brown 2008). Following maternity leave, a returner has been disconnected from the temporal norms of the workplace and this creates a situation where members of the returner-manager dyad might develop very different views on the perceived length and impact of the maternity leave period. We now outline why the disruptions associated with maternity leave, for both the returner and her manager, provide an appropriate context in which to study temporal focus (in)congruence.

\section{Temporal Disruption during Maternity Leave}

Maternity leave represents a time where the pre-existing norms, goals and expectations in the relationship between an employee and their line manager, and the extent to which these are shared, may be significantly altered (Gatrell 2013, Ladge et al. 2018). The return to work after maternity leave also represents a stage in a woman's career with important temporal associations. Although maternity leave is a natural disruption in visibility and workplace relationships, many women report experiencing gradual invisibility and exclusion even before their leave begins (Millward, 2006). Working mothers are often confronted with biased evaluations and assumptions regarding their commitment and performance both at work (Benard and Correll 2010, Glass and Fodor 2018, Luhr 2020) and in the family domain (Okimoto and Heilman 2012). As women transition back into the workplace, their prior investment in their careers and their potential contribution to work in the future become important frames for how they and others think about their careers. The potential impact of temporal focus on processing information about events is increasingly recognized (Levasseur et al. 2020). As such, the temporal focus of returners on the past, present and future of their careers is likely to be an important factor during this time. A focus on past achievement and investment provides a very different context 
for understanding present contribution than a focus solely on present availability or performance. In addition to returners' own focus, the temporal focus of influential others and the extent to which those foci are matched, is likely to have an impact on the return-to-work experience.

The resocialization period, when mothers return to work post-maternity leave, is a critical juncture in a woman's career (Ladge and Greenberg 2015) and managerial support has been found to be central to facilitating adjustment following this career interruption (Ladge et al.2018). Access to support in an organizational context is typically mediated by key workplace relationships, particularly with those in positions of authority. Perhaps the most critical relationship for a woman experiencing a maternity leave transition is the relationship with her line manager, who typically acts as a key source of support and influence at all career stages (Renwick and MacNeil 2002). Manager relationships themselves are also likely to become more salient as employees return to work following leave due to the temporary invisibility created by the period of absence and the need to draw on relationships to reduce uncertainty. When individuals experience a personal transition, via role change, promotion or resocialization after leave, they may struggle to adapt to a new reality (Ibarra and Barbulescu 2010, Ladge and Greenberg 2015). As part of a complex process, individuals are guided by their relationships with others in adapting to their new or revised environment (Sluss and Ashforth 2007).

In essence, managers play a dual role during the return to work after maternity leave. First, the relationship between the manager and returner becomes an important resource in and of itself as a tool for navigating uncertainty during the transition. Yet the paucity of research adopting a relational lens in exploring such a temporal disruption means we do not yet understand the processes underlying how returners and their managers can work together during this time. In adopting a dyadic perspective on the return to work post maternity leave, our research moves beyond questions of individual identity shifts (Hennekam et al. 2019, Hennekam 2016, Ladge and Greenberg 2015) to highlight the central role of temporal focus and relationships during this transitional process. Second, manager's access to resources and influence means their judgements and decisions regarding returners are critical in determining returner access to resources and opportunities. Unfortunately, 
many mothers experience biases in how they are perceived and treated in the workplace with important implications for their careers and health (Hackney, Daniels, Paustian-Underdahl, Perrewe, 2020, Berniell, Berniell, de la Mata, and Marchionni, 2021).

Previous empirical work on motherhood biases has focused on its effects in new or unfamiliar relationships (e.g. Heilman and Okimoto 2008). However, after maternity leave women are generally re-entering established professional relationships and these relationships, especially between the returner and her manager, play an important role in resocialization. There is considerable potential for disparity in how line managers and their employees perceive and process social information and stimuli with implications for both parties (Gibson, Cooper and Conger 2009). Theory on motherhood bias has focused on the incompatibility between cultural expectations of motherhood and employers' perceptions of the ideal worker (Benard and Correll 2010; Glass and Fodor 2018; Reid 2015) and such assumed incompatibility may become more prominent following a temporal disruption due to leave. The disruption of temporal norms creates a situation where members of the dyad might develop different views on the length and impact of the leave period as well as the career prospects of a returner. As such, this study theoretically advances our understanding of the impact of temporal focus fit at a dyadic level. We explore how returners, and their line managers navigate the temporal disruption inherent to maternity leave and the role that temporal focus (in)congruence plays in that process. In particular, we consider the implications of temporal focus (in)congruence for the dyadic relationship between a returner and her manager and for the returner's career.

\section{Method}

\section{Research Setting and Context}

Our research set out to understand how women navigated the disruption of work and career on their return to work after the career interruption of maternity leave. In this paper, we analyze the returner-line manager dyad as a way of understanding how (in)congruence in temporal foci can impact on how returners and their managers view maternity leave within the broader context of the returners' careers. It became apparent during our study that this relationship was central to the 
woman's experience of resocialization post maternity leave and, importantly, shaped the impact of maternity leave on her career and ongoing relationship with her manager.

Our focus was on women who were explicitly identified as high performers and those whom the company would strongly wish to retain. This provided a common characteristic linking the returners, who represented a wide range of industries, and facilitated some comparison across our organizations. The women and their line managers were all employed in professional roles and were educated to a high level. Rather than selecting a single organization where the number of women on leave would be limited at any one time, we approached a number of organizations who could identify high potential women. The woman was also required to have recently returned from leave, within the preceding six months.

Given our focus on high performers, the experiences of the returners in our study are likely to represent the best-case scenarios for returning mothers because their organization was more likely to provide positive supports to facilitate their re-integration and maximize retention. Thus, while our data contain many instances of negative experiences, there are likely many more negative stories out there which are highly relevant to understanding career and relational impact of maternity leave. On a related note, the organization determined who participated in our research and while some sent an open invitation to returners, in many cases, returners and their line managers were handpicked by HR. Thus, we would be naïve to think that our sample is not biased towards more favorable depictions of the transition, which are likely to reflect more positively on the organization.

Our research was conducted in Ireland where organizations must offer 26 weeks maternity leave together with 16 weeks additional unpaid maternity leave, which begins immediately after the end of maternity leave, should the woman choose to take it. At the time of our study, the State paid a standard maternity leave benefit of $€ 235.00$ (approx., \$280) per week and all of the employing firms in our study topped that up to full pay for between 18 and 26 weeks. The vast majority paid full salary as normal for the 26 weeks. Some organizations held back $30 \%$ of the full salary accrued during 
maternity leave to serve as a lump-sum retention bonus if the woman returned to full time work and stayed for at least six months.

\section{Data Collection}

Our primary method of data collection was through semi-structured interviews. Interviews were considered most appropriate as they are flexible enough to facilitate exploration of under-examined phenomena or constructs (King 2004) and in generating micro level data "that presents the phenomenon of interest in its variety and complexity" (Katz 2004, p. 83). Furthermore, from an interpretive perspective, probing techniques were an important tool in understanding the lived experience of the women's resocialization from both their perspectives and the perspectives of their line managers (Kaplan and Orlikowski 2013, McCracken 1988). These probes allowed for depth and comprehension of the data obtained, as interviewees could use and incorporate words and their understanding of ideas in different ways (Berry 2002, Gray 2007).

We were of course conscious of the limitation of post hoc data collection and the potential for retrospective bias in interviewee reflections. We thus took a number of measures to minimize the potential for retrospective bias. Firstly, we used nondirective questions focused on events to gather specific information (Huber and Power 1985). Specifically, we asked informants to describe significant events that they had experienced prior to, during and after the maternity leave and to work through those experience chronologically. We avoided leading questions (e.g., Did your manager value your prior experience?) and speculative ones (e.g., Why was your experience different to others'?). In line with best guidance, we ensured anonymity to encourage candor (McDonald and Eisenhardt 2020). Finally, we triangulated experiences from the perspective of each of our interviewees where possible.

Participant Selection and Characteristics. In developing our sample, we first drew on our own network within industry to pitch this research idea. This represented a 'purposive sampling' (Lincoln and Guba 1985) approach in that we targeted organizations across a range of sectors and industries that we expected to reflect a breadth of approaches to managing maternity leave and which we expected would provide rich information about the phenomenon of interest (Easterby-Smith, Golden- 
Biddle and Locke 2008). We contacted 50 companies, 37 of whom initially agreed to participate in the research. However, following extensive communication and the process to identify suitable participants, we ended up with 27 companies who fully participated in the research. In each of these 27 organizations we set out to interview a high potential woman who returned to work in the previous six months; her line manager; and the HR Director or HR senior manager.

The organizations represent a wide range of industries (e.g. finance, pharmaceuticals, aviation, logistics, technology, public sector). Many are household names and leading global players in their respective sectors. The returning women were identified by their HR Director, who initially invited them to participate. Once they agreed to take part, their line manager was approached by HR. Both had to agree to be interviewed for us to proceed. Once their contact details were passed on to the research team by HR, we contacted the participants individually to set up interview times on site.

Our focus in the current paper is on the returner-manager dyad. This included 27 returners and 27 line manager interviews. Our interest was in the dyadic relationship between the returner and her line manager and so we excluded the HR Director interviews, except where that person also happened to be the line manager. The majority of returners were first time mothers $(78 \%)$ but, as women are more likely to leave work permanently after a second or subsequent child, we also include some second and third time mothers. In most cases, women who were on their second or third maternity leave had different line managers on each return and so were able to contrast their transitions back to work on different occasions.

It should be noted that, while the dyad under study generally existed before and after the transition, a significant minority of the returners had a new manager on return and so, while almost most (93\%) of these were pre-existing relationships, we cannot entirely disentangle the experiences of the post-maternity leave transition reported from the new line management arrangement. That said, the temporal focus adopted by each member of the dyad transcends the tenure of the relationship. Indeed, in one new relationship, the manager clearly adopted a broader temporal lens 
by valuing the returner's reputed past contributions. In short, narrow and broader temporal foci were evidenced across both existing and new line management dyads.

Interviews. As interviews offer insight into people's internal perspectives on social experiences (Lamont and Swidler 2014, Pugh, 2013) they are an appropriate means of exploring returners' and line managers' temporal foci and how they experienced the transition. The interview guide followed a semi-structured approach and our data collection and analysis conformed to standards of rigor for field studies. Interviews were recorded with the interviewees' permission. Our interview guide followed a relatively simple formula as the research process was set up as inductive, in that we expected theoretical constructs to emerge from our data as opposed to firmly directing our data collection (Glaser and Strauss 1967). Interviews lasted between 30 and 75 minutes and averaged 50 minutes for returners and 35 minutes for managers. Most were conducted at the employees' place of work, but three interviews were conducted by conference call due to the participants being located overseas. In line with best practice, during the course of the interviews we continuously made sense of our observations and maintained notes from the field which in turn guided our activities (Dittrich, Guérard and Siedl 2016). After each interview, themes and questions were adapted incrementally, based on new information provided, and subsequently discussed with the next interviewee for validation and additional comment (Eisenhardt 1989).

\section{Data Analysis}

Our analytic approach is best characterized as abductive, rather than the inductive approach we set out with, as we iterated multiple times between our empirical data and theory which led us to form explanatory hypotheses that ultimately became our core theoretical contribution (Ferraro and Beunza 2018, Van Maanen, Sørensen and Mitchell 2007). This recursive interchange between our rich data and emerging conceptual insights, that were related to existing theories, facilitated the creation of new theoretical ideas (Doz 2011, Eisenhardt and Graebner 2007). In effect, data and existing theory were contrasted in tandem (Edmondson and McManus 2007, Gioia, Corley and Hamilton 2013, Van Maanen et al. 2007). Following, Van Maanen et al. (2007), we recognize that good theory emerges 
from "engagement with problems" in the empirical world "but in the service of theorizing" (2007, p.1149). Our process of analysis represented a constant dialogue between the researchers and the emerging theory, with our theorizing being continuously refined as the analysis progressed (Dubois and Gadde 2002).

Our approach here closely resembles 'matching' or 'fitting' of data with theory that has been applied in other abductive studies (Figueira De-Lemos and Hadjikhani 2014). When an unexpected finding emerged, we questioned how we could account for it theoretically and, following our abductive logic, we looked for alternative explanations and utilized the available data to identify the most plausible one (Bryant and Charmaz 2007, Ferraro and Beunza 2018). For example, in considering the importance of relationships, we turned to the literature on socialization, which pointed to the importance of new relationships with others in influencing socialization outcomes (Nifadkar and Bauer 2016, Allen, Eby, Chao and Bauer 2017). However, that literature fell short in explaining the full experience of people returning to the same workplace after an absence which is likely to be influenced by pre-existing relationships that an individual is already heavily invested in. The role of these preexisting relationships and congruence in perspectives on time emerged as key in our data. This led us to the importance of temporal focus during this significant transition.

Consistent with the traditions of qualitative analysis techniques, the modification and evolution of our analysis proceeded along a number of distinct paths (Gioia et al. 2013, Pratt 2009, Saunders, Lewis and Thornhill 2009). Firstly, we transcribed each of our interviews verbatim and summarized sections of the data into key words. We initially focused on individual interviews, then for both interviews in each dyad, and finally across the dyads. This initial 'open coding' resulted in a plethora of 'first order codes'. These in vivo codes were based on the terminology used by interviewees, such as 'adjustment'; 'transition' 'support', 'value' and 'challenge'. We continued to re-read and analyze the transcripts to identify relationships between these first order codes and to ensure adherence to the response terms. 
In the second stage of our coding, we moved to 'categorizing', and the development of 'second order codes'. These second order codes reflected the emergence of categories which we developed alongside the data to reflect relationships, themes and patterns between other potential categories (Saunders et al. 2009). Deriving these categories involved integrating in vivo codes, and terms derived from extant literature (Corbin and Strauss 2008). We repeatedly grouped and regrouped codes found in the data of each interview to search for variations and/or relationships among codes (Petriglieri 2015). At this stage, categories became internally meaningful to the data as well as being externally meaningful to other categories (Saunders et al. 2009). We scrutinized the data for convergent concepts or quotes and their relationships with first order codes. We then merged overlapping categories, grounded in theoretical constructs and related back to key theories, attending particularly to themes that 'leapt out' due to their resonance with extant literature (Corbin and Strauss 2008).

As our analysis advanced, we attached relevant chunks of the data, in the form of rich quotes, to these categories, in a process of 'unitizing' (Saunders et al. 2009). Constant comparison techniques helped in establishing category commonalities and validating whether themes were indeed reportable findings. In this stage, first and second order codes derived from the data, existing literature and emerging themes, were compared with what is known about temporal focus and resocialization from extant research. For example, it was clear that managers had their individual temporal perspective on maternity leave but that the extent to which this was aligned with the returner was also important in terms of the motherhood bias. Table 1 summarizes quotes supporting the role of temporal focus in permitting or inhibiting motherhood bias. Our data analysis shows how a narrow temporal focus fueled bias-affirming perceptions within dyads. This sparked a re-evaluation of the role of temporal focus and in returning to the literature, we recognized how differences in temporal focus resulted in (in)congruence within dyads. Table 2 provides illustrative evidence on the different ways in which temporal (in)congruence was evident in the data.

The final stage in our analysis led us to distil the overarching theoretical framework presented in this article. By repeatedly returning to the interview transcripts, we ensured that our developing 
understanding of how the theoretical categories aggregated accurately represented the data (Locke 2001, Petriglieri 2015). This is summarized in in the four different types of dyads, determined by the temporal focus adopted by each member of the dyad. Figure 1 is a matrix mapping of each of our dyads in terms of where they sit in this typology. This shows how the temporal focus adopted by the returner-line manager dyad can either promote or inhibit motherhood bias.

\section{Findings}

In this section, we build a dyadic theory of how temporal focus (in)congruence in work relationships impacts career and relational outcomes. Through the context of post-maternity leave experiences, we show how returners, and their line managers navigate the return to work following the temporal disruption that is inherent to maternity leave. Our findings illustrate the relational context of this transition and broaden our understanding beyond the individual experiences that have dominated research in the areas of both resocialization (e.g. Ladge and Greenberg 2015) and temporal focus (Shipp and Aeon 2019). Our findings show that congruent temporal focus across dyadic partners yields more positive outcomes, while incongruence inhibits effective resocialization. In particular, a broad congruent temporal focus that takes account of past, present and future contributions to work has the more potential for positive career and relational outcomes. Our findings reframe temporal focus as a relational concept that is more salient during times of temporal disruption and speak to the importance of this process during career transitions.

\section{Narrow vs Broad Temporal Focus and Motherhood Bias}

A critical factor in determining how the transition back to work after maternity leave was experienced was the temporal focus (Shipp et al. 2009) adopted by both members of the dyad. A broader temporal focus comprised an appreciation of past performance alongside a recognition of the potential for future contribution, where maternity leave was viewed in the dyad as merely a brief interlude in a longer-term career. In these cases, the returners often reported a positive transition back after leave. In contrast, where a narrow temporal focus was adopted, a predominantly present focus on the leave and resocialization period resulted in maternity leave being viewed as a major 
disruption and negative experiences were more common. A narrow focus resulted in motherhood status being more prominent and a motherhood bias (Correll et al. 2007) was clearly evident in our data. We argue that this narrow temporal focus fueled bias-affirming perceptions within dyads. Through our analysis, it appeared that a narrow temporal focus promoted biased thinking. On the contrary, a broader temporal focus inhibited motherhood bias (see Table 1).

Maternity leave was much more likely to be viewed as a major disruption and to trigger the motherhood bias when a narrow temporal lens was adopted. Returners described their perceptions of assumptions associated with the onset of motherhood, which meant they were viewed differently on return. As one first time mother noted:

I think there is a bit of an assumption that you've had a baby and you're on the go slow, which is not true, for my case it's not. I might only be here eight to five but, I work hard in those times... When you come back there's not the assumption that you are the same person who left before you had the baby. I'd say the overriding assumption is that things are different for you $(\operatorname{Org} 2 R)$.

One manager spoke about his views on why maternity leave impacts women's performance ratings. Seemingly adopting a very narrow temporal view of maternity leave, he appeared entirely focused on the disruption associated with what he perceived to be a long maternity leave:

...anyone who is out for such a long period of time it's going to take them a few weeks to get back into the work... and it takes them a month to come back in, with the best will in the world the month before they go they will have been in a transition where they are handing over work ... so they won't be as productive as they might be so you are really talking about a year where they haven't really been in work mode, so does it impact? Of course it will (Org 13M).

The returner in this case struggled with the return to work and cried much of the way through her interview. She herself adopted a broader temporal focus and had returned with a desire to progress her career "To be honest, I came back and I feel I want to work really hard and get to the next level. I said to the partner, "I want to send my energy in the right direction"'. Ultimately, she felt let down by 
a lack of support and the prospect of progression was taken away from her by her manager, resulting in many negative emotions for her "it was end of discussion for this year. Quite different, given my expectations...I actually had a doubt, I was a little bit regretful." (Org 13R).

While a future temporal focus, captured by the 'long term' view expressed by some would seem to be important, it is clear from our data that a broader temporal focus was required, where an ability to consider past performance was also positively influential in overcoming motherhood bias. Returners often felt their previous performance could quickly be forgotten "If I was working on clients, people would say: 'have you met these clients?' and I would have been out, maybe, twenty times with them [the clinets] before. It just seemed to be forgotten." (Org 1R). Similarly, another returner contrasted two maternity leaves and different temporal foci adopted clearly emerged as significant in explaining their differing experiences. Returning from her first maternity leave, she had a very difficult transition, which she felt was amplified by a manager who viewed her maternity leave as a complete headache and who she felt had failed to place any value on her past performance.

So, he was already moving against me... He was completely focused on his own career and what he needed to do, and so I left Venus and I came back to Mars... It was horrible, it was really horrible..., you know, I had been working seven days a week, ridiculous hours... for five years trying to deliver out of my socks everywhere and all of that fell away, it was like none of it ever existed (Org 3R).

In her interview, she shared her view that a personal consequence of this experience, was her delaying having a second child for almost five years; "...my daughter is five and a half, so she was nearly five when the second baby was born....before I went on the second maternity leave, I felt I had to recover my reputation internally" (Org 3R). The returner in this case contrasted this with her second, very different return to work experience and reported a much more positive experience the second time around. The adoption of a broader temporal focus had quite an impact on her before her departure on her second maternity leave, evidenced in this quote: 
I think the first thing is he [line manager] didn't treat the maternity leave as a big drama. It was the most critical conversation I've ever had to have with anyone. I was nearly 18 weeks pregnant before I told anybody... but I was just dreading that. But he didn't make a deal about it and he always behaved as if it was a short window... He took a longer-term view, didn't overreact, always behaved like I was coming back. I never had any fear that things would change, and he supported me in the approach that I wanted to take and kept good counsel. (Org 3R).

This was mirrored in the respective line manager's interview, and he spoke at length about it being important not to adopt a present temporal focus when making appointments to roles because that can mean the best person for the role, who might be a woman on maternity leave, is overlooked:

I think it would be important that we don't rule people out unnecessarily... so even in the circumstances where somebody's saying: "I have a role, I need somebody tomorrow, we can't wait around", the reality is they're probably waiting four or five months anyway before the person actually steps in, that could well be the time in which somebody who's not at work today will have returned to work, and they could just as easily have been identified. So, I think it's important that we don't lose sight of that, you know, we don't purposely not consider people for those reasons (Org 3M).

Thus, independently, returners and line managers spoke about the importance of taking a longer-term view and the experiences in these cases were associated with less motherhood bias and more positive resocialization experiences. At times, returners explicitly called out the bias, in other cases, they felt there were simply less opportunities for them now they were mothers (see Table 1). However, what was very apparent in contrasting our cases, is that, at a dyadic level, the degree to which the temporal focus was (in)congruent across both members further influenced how powerful the motherhood bias was in shaping resocialization experiences. We identify four different types of dyads, determined by the temporal focus adopted by each member of the dyad and whether that focus was congruent or not (see Figure 1) and illustrate the significance of temporal focus (in)congruence in the following section. 


\section{Dyadic Temporal Focus (In)Congruence}

In examining the returner-manager dyads, we found cases of matches and mismatches in temporal focus. This resulted in four distinct categories of dyad, presented in Figure 1, according to the temporal foci adopted by the returner and her manager. We describe each of these categories and provide further supporting evidence in Table 2. In line with previous research on the challenges of returning to work post maternity leave (Ladge et al. 2018), there were many examples of women behaving contrary to the motherhood bias while the dyadic partner, the line manager, adopted a narrower temporal focus. We label these dyads as 'Discouraged Returners'. In such cases, the influence of motherhood bias was powerful. Where the manager adopted a narrow temporal focus on the present, he/she was more prone to biased perceptions regarding mothers in the workplace. Returners were more likely to identify themselves as victims of motherhood bias in such cases.

Incongruent temporal focus also emerged in cases where the returner took a rather narrow focus, but the line manager initially adopted a broader temporal focus. We label these dyads as 'Frustrated Managers'. These represent a very small proportion of our cases (Orgs 16, 23). Interestingly though, in these dyads, the initial broad temporal focus of the manager and efforts to consider the returner's longer-term contribution were often dampened pretty quickly in response to a perceived lack of drive on the part of the returner. It should also be noted that managers sometimes reported frustration with other returners rather than the returner in the focal dyad. For instance, in case 8 , the manager reported considerable frustration with a returner who he felt he was going the extra mile for but he perceived the returner was not reciprocating this effort for the organization.

Our data point to two types of dyadic congruence in temporal focus (see Figure 1 and Table 2). First, there were cases where neither party made any explicit effort to neutralize the motherhood bias - where mothers happily assimilated their new identity as a working mother, embraced the characteristics of the stereotype evoked by the motherhood bias and acquiesced to the assumptions that drive the bias. Namely, that work is now far less important than their children. We label these dyads 'Mutual Satisficers'. Finally, and most positively in terms of impact on resocialization outcomes, 
we identified dyads where broader temporal focus was adopted by both members, reducing the reliance on the bias for both parties. We label these dyads as 'Mutual Benefactors'. We first present what we identify as perceptions aligning to motherhood bias held by individuals and then consider how these play out within the dyads.

In one 'Frustrated Manager' case (Org 23), the manager argued that women can self-handicap themselves, where they withdraw from advancement opportunities open to them: "she thought there was somebody better in the competition, I mean that wasn't her decision quite frankly is what I told her. She should have stayed in the competition but that was her thinking which most men would not do... what she didn't realise is that she was very much in with a fighting chance" (Org 23M). However, structural and temporal factors appeared to be impactful in these cases and the importance of time was particular salient to the returner. The returner in this case spoke about her decision not to apply for promotion because it would mean she would have to attend a senior management team meeting at 8am instead of her now agreed 10am start "but that meeting is at eight o'clock, like, crap! ... I wouldn't apply for a position that would necessitate that, because I just can't ... because I want to leave my little lad to school, so, I am looking at job specs in a completely new way" (Org 23R).

For 'Discouraged Returners', an incongruent temporal focus, where the manager adopted a narrow focus, could be quite negative for the returner's experience of returning to work. In one professional services firm, a returner reported that a partner had lashed out at her shortly after her return because she was not fully up to speed. "I mean one of the partners said to me at one point, and this is after a night of four hours of sleep, and he asked me a question and I didn't know the answer and I just said: "I don't know", and he said: "do you have a brain cell in your head?" (Org 1R). Her line manager, though arguing that he was empathetic towards the struggles faced by working mothers to do it all, was of the view that women simply cannot manage to be both mothers and advance to partner level while their children are young: "Some people might not have admitted that in their own minds, family becomes the priority and I'm delighted for them, but it would mean then that they might not be considered right at the leading edge, performance wise" (Org 1M). 
We also identified cases of 'Mutual Benefactors', where both parties adopted a broad temporal focus that served to reduce their reliance on the motherhood bias. This comprised the largest proportion of our cases (see Figure 1). One woman decided to set the path for career progression on her return and was successful in securing a promotion on the verge of starting leave. She perceived this as a hugely positive, particularly given that the role had to be kept open by the line manager for her during her leave. She reported this as "a big leap of faith for him" and the experience to be very positive. She also reported an increased sense of loyalty to the organization.

That did speak volumes to me about him holding open the role for somebody he didn't know... First of all, holding off until I came back but also that he didn't really know me. So, I was going to have a new boss as well, that I had no experience with before...the fact that the position was being held for me was very positive for me and for other women going on maternity leave. So, fair play to [the manager] and the company for that. (Org 12R).

Her new manager clearly adopted a broader temporal focus. Her role was kept open for her while she was on leave, and he described her as the "outstanding candidate" based on her reputed past performance within the organization. While challenging for him in absorbing her workload during the leave, it was clear that he also took a long-term view, referencing a broader temporal focus despite the pressure that resulted for him personally.

We have a high proportion of maternity leave at any one time... the challenge is how do we manage the disruption to which it gives rise... There's a general culture that it really adds to our whole work-life balance that we promote and we value. So, it's really about how do we cover the gaps, it's as simple as that frankly. At the same time, we have to make sure that it doesn't have any negative impact on, that people feel their careers are not impacted by it. (Org 12M). In some congruent cases, the line manager and returner both openly opined their agreement with the stereotype evoked by the motherhood bias. We label these cases as 'Mutual Satisficers' the returners chose not to counteract the motherhood bias and instead embraced the expectations that it brought. In these dyads, both partners are acquiescent to the motherhood bias and generally 
pragmatic about it. It was clear that the woman decided to pull back from work as a result of her own shifting priorities. This promotes the bias and, as alluded to by one manager, reinforced his own biases in this regard:

They are more chatty about the children... there's no benefit to the company in my experience, because even their focus while they are here becomes talking about the children or wondering about the children or ringing home to see how the children are or going to the doctor with the child or whatever and don't get me wrong that's natural. (Org 10M).

The returner did not challenge this biased view, arising from a narrow, present-oriented temporal focus but rather admitted her own shifting priorities and focus on the present, noting that she intends to slow down for a while: ... because you re-adjust your priorities and right now family is the priority (Org 10R).

There were other cases of 'Mutual Satisficers', where the apparently biased views of managers were matched by the desires of the returner to reduce her commitment to work. In one case, in a professional services firm, the returner firmly acknowledged that she needed to remove the stress from her life and opted to move to a non-client facing role with less opportunity for career progression. While there is a degree of acceptance in the language these returners use, we do not rule out the possibility that the time commitments expected in such organizations mean that returners perceived they had little choice but to satisfice or rationalize their choices.

after I had my first child, I just found the juggle was just too much in terms of client work; client work is not a nine-to-five job... Maybe it's just a paranoia of women returning to work, but I think people are reluctant to say: "I have to go to get my kids". You feel like you're not up to the job, or you're letting the team down, so I found that removing that stress from my life, now I can work away, leave when I need; that was huge (Org $7 R)$.

This case points to the potential impact of the temporal focus adopted. More generally, our data support the idea that any mismatch of temporal focus between the returner and her manager can significantly hamper resocialization, while congruence within the dyad fosters more positive 
outcomes. We now describe the resocialization outcomes arising from the different foci described, first, exploring perceived career impact followed by the relational impacts that our dyads experienced.

- Figure 1 About Here

- Table 2 About Here -

\section{Career and Relational Outcomes of Temporal Focus (In)Congruence}

Overall, in the two incongruent dyad categories, the individual who adopts the broad temporal focus perceives the experience more negatively. For the line manager, the impact is largely relational and for the returner, the impact is largely perceived as career related. We identified positive and negative career outcomes for our returners (see Table 3). The self-efficacy challenges experienced by women returning to work after periods of leave have been highlighted in previous work (e.g. Ladge and Greenberg, 2015). Some of our cases mirror these findings, where women did fall behind due to absence, particularly where organizational change continued at a pace during this time. This acknowledges the temporal disruption associated with periods of maternity leave.

In one way you've had a really long break from all of that part of your life... in one way you should be completely refreshed... but in another way you've missed out on an awful lot, people are talking about projects that you haven't been a part of, there can be quite a steep learning curve in terms of getting back into the groove of where you were before... (Org 12R).

However, the temporal focus adopted on return was important in positioning this disruption that is, a broader temporal focus meant that disruption due to motherhood had less of a perceived impact on career prospects while a narrow temporal focus amplified the impact on career. Typically, returners in the congruent focus dyads reported the most positive career impact or satisfaction, while those in the incongruent dyads were more likely to perceive that their career progression had stalled, whether by choice or not. Numerous 'Discouraged Returners', particularly those in client facing roles, reported a significant erosion of their role, where they lost their clients or caseloads (Cases 1, 5, 13, 18). Without the ability to look back at a woman's contributions before maternity leave, role erosion was a frequent negative outcome: 
they got a guy on board, and I trained him, he had no experience at all, so, it was very challenging because I had to get the whole project over to him. So, when we are in front of a client, I have to promote him and put him in the front and let him take the credit, but I know there was a lot of work behind there, to bring him to that level (Org 13R).

However, there were many returners, particularly in the 'Mutual Benefactors' category, who found the leave period to be beneficial for their careers, facilitated by a broader temporal focus (see Table 3). These returners reported they had 'headspace' to consider their next career move or, in many instances, they returned with a newfound sense of focus and ability to prioritize. In these cases, returners appeared to look beyond the immediate point of return to what their careers mean to them. Coming back from maternity leave, I have realized how important work is to me, just work, you know, in that you are productive every day but also just having your own independence. So work has actually become a more important factor in my life in a very positive way compared to before. It was just like, over, well it was just all-consuming, and I had no sort of outside thing to get me away from work (Org 24R).

In line with work-life enrichment theory (Greenhaus and Powell 2006), our data also point to a positive impact of time away from work on reentry experiences: "I need to find that hour or two to close stuff out or be more ruthless about what I attend or what I don't attend so I suppose on the positive side I am much more focused and I am much more ruthless about what I do and what I don't do. I delegate much better than what I probably did in the past so there's definitely a positive side to it (Org 15R).

-Table 3 Here-

Alongside the impacts on returners' careers, our data illustrate the potential for meaningful relational impact during the transition (see Table 4). In particular, the impact on dyadic relationships in our study depended on the temporal focus adopted - and the extent to which there was an (in)congruent temporal focus across both members of the dyad. We identified two different types of relationship impact; negative, typically in incongruent dyads, where there was reduced trust in either the manager or the returner; and positive, typically amongst 'Mutual Benefactors', where the 
relationship was enhanced, particularly from the perspective of the returner. Interestingly, for the 'Mutual Satisficers' dyads, where congruence in temporal focus was also evidenced, there seemed to be little or no salient impact on the relationship. However, aside from this category, the potential for this transition to impact on the relationship was clear and, in many instances, changes in trust (Mayer, Davis and Schoorman 1995) characterized this impact. It seemed this return-to-work period was a time when women can feel particularly vulnerable, as one 'Discouraged Returner' reported:

one of those senior men that I mentioned to you, that I felt punished me, and I found that very difficult to deal with, just because I did see him as someone I could turn to in the past and I had turned to in the past on issues. I felt he really let me down when I was feeling very insecure (Org 21R).

While some returners interpreted their manager's behavior as a lack of manager trustworthiness, particularly integrity or benevolence (see Table 4), others felt less trusted themselves from a competence perspective (Salamon and Robinson 2008).

I'm a bit bored at work and I'm a bit disappointed that I'm not doing the same level of stuff that I was doing before, but I was working for different people before, so, maybe they understood my abilities a bit better (Org $5 R$ ).

On the contrary, in the case of a congruent, broader view, returners often reported experiencing high levels of felt trust and shared how valuable this was to them in managing the juggle between work and family responsibilities "that's the one thing I'd say for my manager, I think I've built up enough trust with them that if I did have to phone in and say, 'I'm really stuck today', that would be okay. He knows that I wouldn't be taking the piss, for want of a better word" (Org 23R). In this instance, the manager was still frustrated with the returner's decision to rule herself out of some opportunities, but argued he continued to support her choices. Indeed, benevolent signals from colleagues in general to reintegrate the returner could result in a very compelling response:

Someone values what you're saying......It's a real light bulb moment, you think: "god, I really like the people I work with... it makes you feel like you're a part of a family... there are people who 
are genuinely interested in how you got on... I certainly got the sense that they were really excited to have me back, and there's loads they wanted me to help with, and kind of feeling valued, and feeling important." (Org 7R).

One case classified as a 'Mutual Benefactor' returner, who was promoted to partner in a professional services firm on return from maternity leave, spoke at length about how positive the experience was and how critical her manager was in supporting her to have a family while on the partner track. Ultimately, her sense of connection to the manager themselves and to the organization as a whole was enhanced:

now, you know, I feel ... Like, I don't want to say it feels like a family because that's a bit ... but it feels like it's more than an employer kind of connection... I feel very loyal to [the company] and also to the individual who kind of, you know, helped me navigate my career around, you know, that so yeah, no, so I wouldn't be going anywhere." (Org 22R).

While many of our cases show these positive relational impacts, perceived breaches of trust were also relatively frequent during this time and damaged the dyadic relationship, particularly in incongruent cases (see Table 4). A breach in the eyes of a 'Frustrated Manager' were at times related to norms of reciprocity being broken and a feeling that the returner was not likely to put the manager or organization's interests above her own. However, it could also be because the manager believes in supporting women but that they self-handicap themselves by ruling themselves out of competitions for family reasons "she had decided that basically she didn't want the job but she didn't want the job because there was a job coming up at the same level that was closer to home, that was a decision she made and I guess she made it because of family reasons" (Org 23M). Though he also sensed that mothers do not want to commit to the work required, even when they are encouraged to progress "The reality is if you want to get to a senior level, whether you're a man or a woman, you're going to be working long hours, intensely, within the organization because that's what it takes in any organization (Org 23M)". 
From the returner perspective, there were also numerous 'Discouraged Returner' cases who reported reduced trust in their managers due to perceived breaches (Cases 1, 15, 18, 20, 21). One returner, a single parent, spoke about a trust breach experienced as a result of how her manager reneged on flexible working arrangements they had agreed in advance of her return:

that was pulled for no apparent reason, so that was quite difficult. So that kind of just threw everything up in the air in terms of my plans for childcare... it was just, it was very upsetting at the time, and I think it was probably the first time I ever cried in work. I was very disappointed in [my manager] (Org 27R).

-Table 4 Here-

\section{Discussion}

In this research, we consider how temporal focus is influential at a relational level and how temporal focus (mis)matches between a manager and employee might impact on relational and career outcomes. We drew on maternity leave as a phenomenological temporal disruption to explore the temporal dynamics at play within a significant workplace relationship and to understand how resocialization may be impacted by the returner and her manager's shared or divergent temporal foci. We illustrate how a congruent, broader temporal focus can reduce reliance on the motherhood bias by facilitating a more holistic and systematic consideration of past, present and future contributions. In such instances, members of the dyad were more likely to recognize the full period of the returner's career. Conversely, where one member of the dyad held a narrow temporal focus, resulting in an incongruent temporal focus, this promoted evaluations more aligned with stereotypes evoked by the motherhood bias.

In the context of post maternity leave navigation, we identified four types of returner-manager dyads - depicted in Figure 1 - and these are associated with different outcomes for the relational partners. Mutual benefactors, those with a congruent, broad temporal focus benefit from the most advantageous outcomes. In contrast, the poorest perceived outcomes were for discouraged returners, where a mismatched temporal focus at the dyadic level resulted in considerable disenchantment for 
the returner. A matched, narrow temporal focus, in the case of mutual satisficers, was primarily associated with acceptance for both members of the dyad, where both returner and manager acknowledged that the returner's career would slow down for a while. Finally, mismatch occurred for frustrated managers where their initial, broad temporal outlook was dampened quickly by a narrow temporal focus on the part of the returner, ultimately leading to frustration on the part of the manager. In short, our findings show how dyadic temporal focus matters. The extent to which members held congruent views of maternity leave as a brief interlude - driven by a broader temporal focus - as opposed to a major disruption, resulting from a narrow, present focus, further influenced how temporal foci shaped return-to-work experiences and outcomes.

\section{Contributions to Theory}

We offer a number of theoretical extensions. First, we contribute to the literature on temporality. In responding to calls for relational perspectives on the temporal context, particularly in workplace relationships (Shipp and Aeon 2019), our research highlights the importance of temporal focus in influencing outcomes at an individual and dyadic level within the line manager-returner relationship. Thus, temporal focus has a wider impact than is typically portrayed in the literature. We illustrate the potential for (in)congruence in temporal focus within workplace relationships to impact considerably on relational and career outcomes. Specifically, we show how positive relational outcomes most typically arise for mutual benefactors, characterized by alignment in temporal focus that appreciates and balances the past, present and future. We extend work by Briker et al. (2020) and Waller et al. (2020) on the consequences of (mis)fit of past temporal focus between leaders and their teams and suggest that, in this context, alignment in a general sense exerts an influence and it is not restricted to alignment of a single temporal lens.

Building on recent work on the differential outcomes of past, present and future temporal foci (e.g. Shipp, in press) we demonstrate how a narrow, present focus on maternity leave transitions permits evaluations that are more prone to motherhood bias. This contrasts with previous work which has highlighted negative outcomes associated with a past focus while present and future foci are 
positioned as a mixed blessing (Levasseur et al. 2020). We show that rather than any particular focus being more or less advantageous than another, a broader temporal focus allows returners and their managers to consider past investment and potential future contribution alongside the more immediate experiences of the return to work after maternity leave.

We also extend our understanding of maternity leave transitions by introducing the consideration of temporal characteristics. While all career transitions involve an element of dynamic unfolding over time (Ashforth 2001), the return to work post maternity leave represents a unique context where both dyadic members must navigate a period of temporal disruption and subsequent reintegration. Temporary invisibility in the organization is associated with career penalties (McDonald et al. 2008). The accompanying interruption of workplace temporal rhythms creates a situation where members of the dyad might develop very different subjective views on the impact of the maternity leave period. Our research extends the extant literature in highlighting the value of a temporal lens for advancing our understanding of post maternity leave resocialization experiences and, in particular, the significant role of temporal focus (in)congruence between the returner and her manager in either promoting or inhibiting motherhood bias after a period of disruption. In so doing, we identify four different types of dyad, determined by the (in)congruence of the partners' respective temporal foci and illustrate the typical career and relational outcomes associated with each.

Our research on maternity leave transitions is the first to adopt a fully relational lens and to consider the temporal dimensions of this career interruption. We show that maternity leave does not merely involve an individual career adjustment (e.g. Ladge and Greenberg 2015; Ladge et al. 2018) but that the response to the temporal disruption is shaped by relational factors and, in particular, the temporal focus adopted within the dyad and whether that is shared or divergent. As such, maternity leave is not only a potential pitfall as detailed in previous studies (Gatrell 2013; Ladge and Greenberg 2015) but a juncture at which a woman's career can be strengthened and the managerial working relationship can be enhanced, where both parties adopt a broader temporal focus. We build on Ladge and Greenberg's (2015) research on resocialization by demonstrating that a shared, broader temporal 
focus plays a significant role in confronting the uncertainties associated with career transitions and further explains why some women adapt effectively and why some struggle when they negotiate the return to work. More broadly, we argue that extant theorizing has been overly reliant on an identity perspective. This limited focus fails to consider the powerful role that temporal focus plays and that a congruent broad focus helps to counteract motherhood bias, a stereotype that may be amplified when a woman has been absent from the workplace for parenting reasons.

\section{Limitations and Future Research Directions}

Our paper draws on rich, qualitative, dyadic data to explore a neglected area of temporal focus theory in the context of a common and critical career transition. We discuss the key methodological limitations and steps we took to mitigate them in our methodology section. However, despite the significant strengths of our approach, our research has additional limitations and highlights a number of unexplored issues that require further research and theorizing. First, resocialization is a transition that takes place over time and as such longitudinal data would be helpful in understanding how temporal processes change and develop over the course of this transition. In particular, future longitudinal research may more reliably tease out how and why some dyads move from congruent temporal foci before the disruption to incongruent after it. In addition, longer term longitudinal studies might be useful in determining how and when this incongruence can be resolved and the longer-term impacts of temporal focus fit on careers and workplace relationships.

Second, we also tentatively point to the role of heuristic thinking, where a small body of evidence suggests that temporal focus might influence reliance on heuristic versus systematic thinking (Levasseur et al. 2020, Tang, Kacmar, Busenitz 2012). While our interviews did not explicitly address this process in depth, future research might draw on dual process theory (e.g. Evans 1984, 2008) to help explain the mechanisms linking temporal focus to thinking shaped by the motherhood bias. Dual process theory presents two distinct processes consisting of an implicit, unconscious and automatic process and an explicit, conscious and deliberate process (Kahneman 2003). Understanding how a broader temporal focus can illicit more reasoned thought in relation to career judgements, by 
returners themselves and by their line managers, would be a fruitful avenue for future research. The dual process lens also highlights avenues for future research on the wider context in which the line manager-returner relationship is situated. For instance, previous applications of dual processing have emphasized the role of the environment and particularly of the level of risk and uncertainty in that environment in influencing the reliance on heuristic and systematic information processing (Klein, 1989, van der Werff et al., 2019). In this context, structural and cultural facets of the organization, the industry or geographical context in which returner dyads are working might play a role in influencing how maternity leave and the return to work is viewed and experienced.

Relatedly, it is likely that other relationships in a returner's life will be important in influencing both the return to work after career interruptions and longer-term career outcomes. Our focus is on the professional relationship of the line manager-returner dyad. However, other working relationships are also likely to be important and the role of temporal fit across teams and following disruptions due to other reasons would refine our understanding of the underlying mechanisms at play. Indeed, some of our returners mentioned the role of co-workers in supporting their return or taking advantage of their temporary invisibility. Furthermore, while we did not explicitly set out to capture data on life outside of the organizational context, it was clear from a number of our cases that personal relationships also played a role. For instance, some of our returners reported considerable support from their partners who agreed to step back from their own careers temporarily to meet family childcare needs and facilitate the returner in re-establishing their careers following leave. Although this focus was beyond the scope of our paper, an increasing body of evidence demonstrates spillover between work and family or life domains (Kossek, Perrigino, and Rock 2020) and the influence of personal relationships is an important area for future study. The crossover of temporal focus from one partner's workplace to another may be a useful lens to adopt in research of dual career negotiation in the home domain.

\section{Practical Implications}


This research also offers important lessons for practice. Our study highlights those interruptions to the normal rhythm of workplace relationships may amplify the importance of temporal focus fit. A failure to recognize and acknowledge such shifts may lead to frustration for one or both members of the dyad. Following any kind of temporal disruption, such as maternity leave in the case of this study, but also other types of leave or secondments, line managers and returners should be encouraged to create an open dialog within the dyad to enable effective resocialization (Collings, Freeney and van der Werff 2018). Our results suggest that congruence in temporal perspective results in more positive outcomes for the relationship and the returner's career in all cases but particularly when that congruence has a broad temporal focus. This open dialog would help returners and their line managers to reach a mutual understanding about this transition and create a forum in which assumptions about priorities can be examined and, if necessary, challenged. Transitions following disruption can be challenging to navigate and our findings suggest that relational partners fare better when they are on the same page and where they are capable of adopting a broader temporal focus.

\section{Conclusion}

This study provides new insights into the role of temporal focus (in)congruence in shaping how dyadic partners negotiate their relationship during a resocialization transition, in this case, post maternity leave. Our research extends research on temporal focus by adopting a relational lens and underscoring the significance of fit between dyadic partners as they negotiate a temporal disruption. It further provides insights into women's experiences of returning to work following maternity leave and how this transition acts as a critical juncture for impact on women's careers and professional relationships. A broad temporal focus in the returner-line manager relationship allows women and their professional relationships to thrive on their return to work. Our relational perspective offers a new research agenda for temporal scholars and aims to prompt a deeper scholarly consideration of the potential for a shared, broad temporal focus to yield better outcomes for both individuals and organizations.

\section{References}


Alipour KK, Mohammed S, Martinez PN (2017). Incorporating temporality into implicit leadership and followership theories: Exploring inconsistencies between time-based expectations and actual behaviors. Leadersh. Q. 28(2): 300-316.

Allen TD, Eby LT, Chao GT, Bauer TN (2017) Taking stock of two relational aspects of organizational life: Tracing the history and shaping the future of socialization and mentoring research. J. Appl. Psych. 102: 324-337.

Ancona D, Chong CL (1996) Entrainment: Pace, cycle, and rhythm in organizational behavior. Res. Organ. Behav. 18: 251-284.

Ancona DG, Okhuysen GA, Perlow LA (2001). Taking time to integrate temporal research. Acad. Manag. Rev. 26(4): 512-529.

Ashforth BE (2001) Role transitions in organizational life: An identity-based perspective (Mahwah, NJ: Erlbaum).

Ashforth BE, Saks AM (1995) Work-role transitions: A longitudinal examination of the Nicholson model. J. Occup. Organ. Psych. 68: 157-175.

Benard S, Correll SJ (2010). Normative discrimination and the motherhood penalty. Gend. Soc. 24(5): 616-646.

Berniell I, Berniell L, De la Mata D, Edo M, Marchionni M (2021). Gender gaps in labor informality: The motherhood effect. J. Dev. Econ. 150: 102599.

Berry JM (2002) Validity and reliability issues in elite interviewing. Polit. Sci. Politics 35: 679-682.

Briker R, Walter F, Cole MS (2020) The consequences of (not) seeing eye-to-eye about the past: The role of supervisor-team fit in past temporal focus for supervisors' leadership behavior. J. Organ. Behav. 41: 244-262.

Bryant A, Charmaz K (2007) The SAGE Handbook of Grounded Theory (Sage, Thousand Oaks, CA).

Cojuharenco I, Patient D, Bashshur MR (2011) Seeing the "forest" or the "trees" of organizational justice: Effects of temporal perspective on employee concerns about unfair treatment at work. Organ. Behav. Hum. Decis. Process. 116: 17-31. 
Cole MS, Shipp AJ, Taylor SG (2016) Viewing the interpersonal mistreatment literature through a temporal lens. Organ. Psych. Rev. 6: 273-302.

Collings, Freeney Y, van der Werff, L. (2018). How Companies Can Ensure Maternity Leave Doesn't Hurt Women's Careers'. Harv. Bus. Rev. https://hbr.org/2018/09/how-companies-can-ensurematernity-leave-doesnt-hurt-womens-careers

Corbin J, Strauss A (2008) Basics of qualitative research: Techniques and procedures for developing grounded theory, 3rd ed. (Thousand Oaks, California: Sage).

Correll SJ, Benard S, Paik I (2007) Getting a job: Is there a motherhood penalty? Am. J. Sociol. 12: 1297-338.

Dittrich K, Guérard S, Seidl D (2016) Talking about routines: The role of reflective talk in routine change. Organ. Sci. 27(3): 678-697.

Doz Y (2011) Qualitative research for international business. J. Int. Bus. Stud. 42(5): 582-590.

Dubois A, Gadde LE (2002) Systematic combining: an abductive approach to case research. J. Bus. Res. 55(7): 553-560.

Easterby-Smith M, Golden-Biddle K, Locke K (2008) Working with pluralism: Determining quality in qualitative research. Organ. Res. Methods, 11(3): 419-429.

Edmondson AC, McManus SE (2007) Methodological fit in management field research. Acad. Manag. Rev. 32(4): 1246-1264.

Eisenhardt KM (1989) Agency theory: An assessment and review. Acad. Manag. Rev. 14(1): 57-74.

Eisenhardt KM, Graebner ME (2007) Theory building from cases: Opportunities and challenges. Acad. Manag. J. 50(1): 25-32.

Eldor L, Fried Y, Westman M, Levi AS, Shipp AJ, Slowik LH (2017). The experience of work stress and the context of time: Analyzing the role of subjective time. Organ. Psychol. Rev. 7(3): 227-249. Evans JSB (1984) Heuristic and analytic processes in reasoning. Brit. J. Psychol., 75(4): 451-468. Evans JSB (2008) Dual-processing accounts of reasoning, judgment, and social cognition. Annu. Rev. Psychol. 59: 255-278. 
Ferraro F, Beunza D (2018) Creating Common Ground. Communicative action model of dialog in shareholder engagement. Organ. Sci. 29(6): 1187-1207.

Figueira-de-Lemos F, Hadjikhani A (2014) Internationalization processes in stable and unstable market conditions: Towards a model of commitment decisions in dynamic environments. J. World Bus. 49(3): 332-349.

Gatrell CJ (2013) Maternal body work: How women managers and professionals negotiate pregnancy and new motherhood at work. Hum. Relat. 66: 621-644.

Gibson CB, Cooper CD, Conger JA (2009) Do you see what we see? The complex effects of perceptual distance between leaders and teams. J. Appl. Psych. 94: 62-76.

Gioia DA, Corley KG, Hamilton AL (2013) Seeking qualitative rigor in inductive research: Notes on the Gioia methodology. Organ. Res. Method. 16(1): 15-31.

Glaser B, Strauss A (1967) The Discovery of Grounded Theory. Strategies for Qualitative Research (Chicago, Aldine).

Glass C, Fodor E (2018). Managing motherhood: job context and employer bias. Work. Occup. 45(2): $202-234$

Gough M, Noonan M (2013). A review of the motherhood wage penalty in the United States. Sociol. Compass 7: 328-342.

Gray DE (2007) Facilitating management learning developing critical reflection through reflective tools. Manag. Learn. 38(5): 495-517.

Greenhaus JH, Powell GN (2006) When work and family are allies: A theory of work-family enrichment. Acad. Manag. Rev. 31(1): 72-92.

Hackney KJ, Daniels SR, Paustian-Underdahl SC, Perrewé PL, Mandeville A, Eaton AA (2020). Examining the effects of perceived pregnancy discrimination on mother and baby health. $J$. Appl. Psychol.

Heilman ME, Okimoto TG (2008) Motherhood: a potential source of bias in employment decisions. J. Appl. Psychol. 93: 189-198. 
Hennekam S (2016) Identity transition during pregnancy: The importance of role models. Hum. Relat. 69: 1765-1790.

Hennekam S, Syed J, Ali F, Dumazert JPA (2019) Multilevel perspective of the identity transition to motherhood. Gend. Work Organ. 26: 915-933

Holman EA, Silver RC (2005). Future-oriented thinking and adjustment in a nationwide longitudinal study following the September 11th terrorist attacks. Motiv. Emot. 29(4): 385-406.

Huber G, Power D (1985) Retrospective reports of strategic-level managers: Guidelines for increasing their accuracy. Strateg. Manag. J. 6: 171-180.

Ibarra H, Barbulescu, R (2010) Identity as narrative: Prevalence, effectiveness, and consequences of narrative identity work in macro work role transitions. Acad. Manag. Rev. 35: 135-154.

Kahneman D (2003) A perspective on judgement and choice. Am. Psychol. 58(9): 697-720.

Kaplan S, Orlikowski WJ (2013) Temporal work in strategy making. Organ. Sci. 24(4): 965-995.

Katz J (2004) Commonsense criteria. In C Ragin, J Nagel, P White (Eds.), Proceedings of the "Scientific Foundations of Qualitative Research" Workshop (Arlington, VA: NSF), 77-80.

Keller JR, Kehoe RR, Bidwell MJ, Collings DG, Myer A.(2020). In with the old? Examining when boomerang employees outperform new hires. Acad. Manag. J.

King N (2004) Using interviews in qualitative research. In C Cassell G Symon (Eds), Essential guide to qualitative methods in organizational research. (London: Sage), 11-22.

Klein HJ (1989) An integrated control theory model of work motivation. Acad. Manag. Rev. 14(2): $150-172$.

Kossek EE, Perrigino M, Rock AG (2020) From ideal workers to ideal work for all: A 50-year review integrating careers and work-family research with a future research agenda. J. Vocat. Behav. ePub ahead of print October 20, https://doi.org/10.1016/j.jvb.2020.103504.

Ladge JJ, Greenberg DN (2015) Becoming a working mother: Managing identity and efficacy uncertainties during resocialization. Hum. Resour. Manag. 54: 977-998. 
Ladge JJ, Humberd BK, Eddleston KA (2018) Retaining professionally employed new mothers: The importance of maternal confidence and workplace support to their intent to stay. Hum. Resour. Manag. 57: 883-900.

Lamont M \& Swidler A (2014). Methodological pluralism and the possibilities and limits of interviewing. Qual. Sociol., 37(2), 153-171.

Leroy S, Shipp AJ, Blount S, Licht JG (2015) Synchrony preference: why some people go with the flow and some don't. Pers. Psychol. 68:759-809

Levasseur L, Shipp AJ, Fried Y, Rousseau DM, Zimbardo PG (2020) New perspectives on time perspective and temporal focus. J. Organ. Behav. 41(3): 235-243.

Lincoln YS, Guba EG (1985) Naturalistic Inquiry, Vol. 75. London: Sage Publications.

Little LM, Major VS, Hinojosa AS, Nelson DL (2015) Professional image maintenance: How women navigate pregnancy in the workplace. Acad. Manag. J. 58: 8-37.

Locke, KD (2001). Grounded theory in management research. London: Sage Publications.

Luhr S (2020). Signaling parenthood: Managing the motherhood penalty and fatherhood premium in the US service sector. Gend. Soc. 34(2): 259-283.

Mayer, RC, Davis, JH, Schoorman, FD (1995) An integrative model of organizational trust. Acad. Manag. Rev. 20(3): 709-734.

McCracken G (1988) The long interview, Vol. 13 (Sage Publications).

McDonald P, Bradley L, Brown K (2008) Visibility in the workplace: still an essential ingredient for career success? Int. J. Hum Resour. Manag. 19: 2198-2215.

McDonald RM, Eisenhardt KM (2020). Parallel play: Startups, nascent markets, and effective business-model design. Adm. Sci. Q. 65(2): 483-523.

Methot JR, Lepak D, Shipp AJ, Boswell WR (2017). Good citizen interrupted: Calibrating a temporal theory of citizenship behavior. Acad. Manag. Rev. 42(1): 10-31.

Millward $\amalg$ (2006) The transition to motherhood in an organizational context: An interpretative phenomenological analysis. J. Occup. Organ. Psychol. 79: 315-333. 
Nifadkar SS, Bauer TN (2016) Breach of belongingness: Newcomer relationship conflict, information, and task-related outcomes during organizational socialization. J. Appl. Psychol. 101: 1-13.

Orlikowski WJ, Yates J (2002) It's about time: Temporal structuring in organizations. Organ. Sci. 13(6): 684-700.

Petriglieri JL (2015). Co-creating relationship repair: Pathways to reconstructing destabilized organizational identification. Adm. Sci. Q., 60(3), 518-557.

Pratt MG (2009) From the editors: For the lack of a boilerplate: Tips on writing up (and reviewing) qualitative research. Acad. Manag. J. 52 (5): 856-862.

Pugh (2013) What good are interviews for thinking about culture? Demystifying interpretive analysis. Am. J. of Cult. Sociol. 1: 42-6

Reid E (2015) Embracing, passing, revealing, and the ideal worker image: How people navigate expected and experienced professional identities. Organ. Sci. 26(4): 997-1017.

Renwick D, MacNeil CM (2002) Line manager involvement in careers. Career Dev. Int. 7: 407-414. Rush J Grouzet FM (2012). It is about time: Daily relationships between temporal perspective and well-being. J. of Pos. Psych. 7(5): 427-442.

Salamon, SD, Robinson, SL (2008) Trust that binds: The impact of collective felt trust on organizational performance. J. Appl. Psychol. 93(3): 593.

Saunders M, Lewis P, Thornhill A (2009) Research methods for business students (Pearson Ed). Shipp AJ (in press). Temporal focus: A review of the past with an eye to the future. In F. Grouzet (Ed.), Oxford Handbook of Psychology of Time Travel and Temporality (Oxford University Press: Oxford, UK).

Shipp AJ, Aeon B (2019) Temporal focus: Thinking about the past, present, and future. Curr. Opin. Psychol. 26: 37-43.

Shipp AJ, Edwards JR, Lambert LS (2009) Conceptualization and measurement of temporal focus: The subjective experience of the past, present, and future. Organ. Behav. Hum. Dec. Process. 110(1): $1-22$. 
Shipp AJ, Richardson, H (2019) The Impact of Temporal Schemata: Understanding When Individuals Entrain versus Resist or Create Temporal Structure. Acad. Manag. Rev. ePub ahead of print July 19, https://doi.org/10.5465/amr.2017.0384.

Sluss DM, Ashforth BE (2007) Relational identity and identification: Defining ourselves through work relationships. Acad. Manag. Rev. 32: 9-32.

Swider BW, Liu JT, Harris TB, Gardner RG (2017). Employees on the rebound: Extending the careers literature to include boomerang employment. J. App. Psychol. 102(6): 890-909.

Tang J, Kacmar KMM, Busenitz L (2012) Entrepreneurial alertness in the pursuit of new opportunities. J. Bus. Ventur. 27(1): 77-94.

van der Werff L, Legood A, Buckley F, Weibel A, de Cremer D (2019) Trust motivation: The selfregulatory processes underlying trust decisions. Organ. Psychol. Rev. 9(2-3): 99-123.

Van Maanen J, Sørensen JB, Mitchell TR (2007) The interplay between theory and method. Acad. Manag. Rev. 32: 1145-1154.

Waller MJ, Franklin AE, Parcher DB (2020). Time perspective balance and team adaptation in dynamic task contexts. J. Organ. Behav. 41(3): 263-275.

Zacher H (2014). Individual difference predictors of change in career adaptability over time. J. of Voc. Beh. 84(2): 188-198.

Zimbardo P, Boyd J (2008). The time paradox: The new psychology of time that will change your life. New York: The Free Press. 


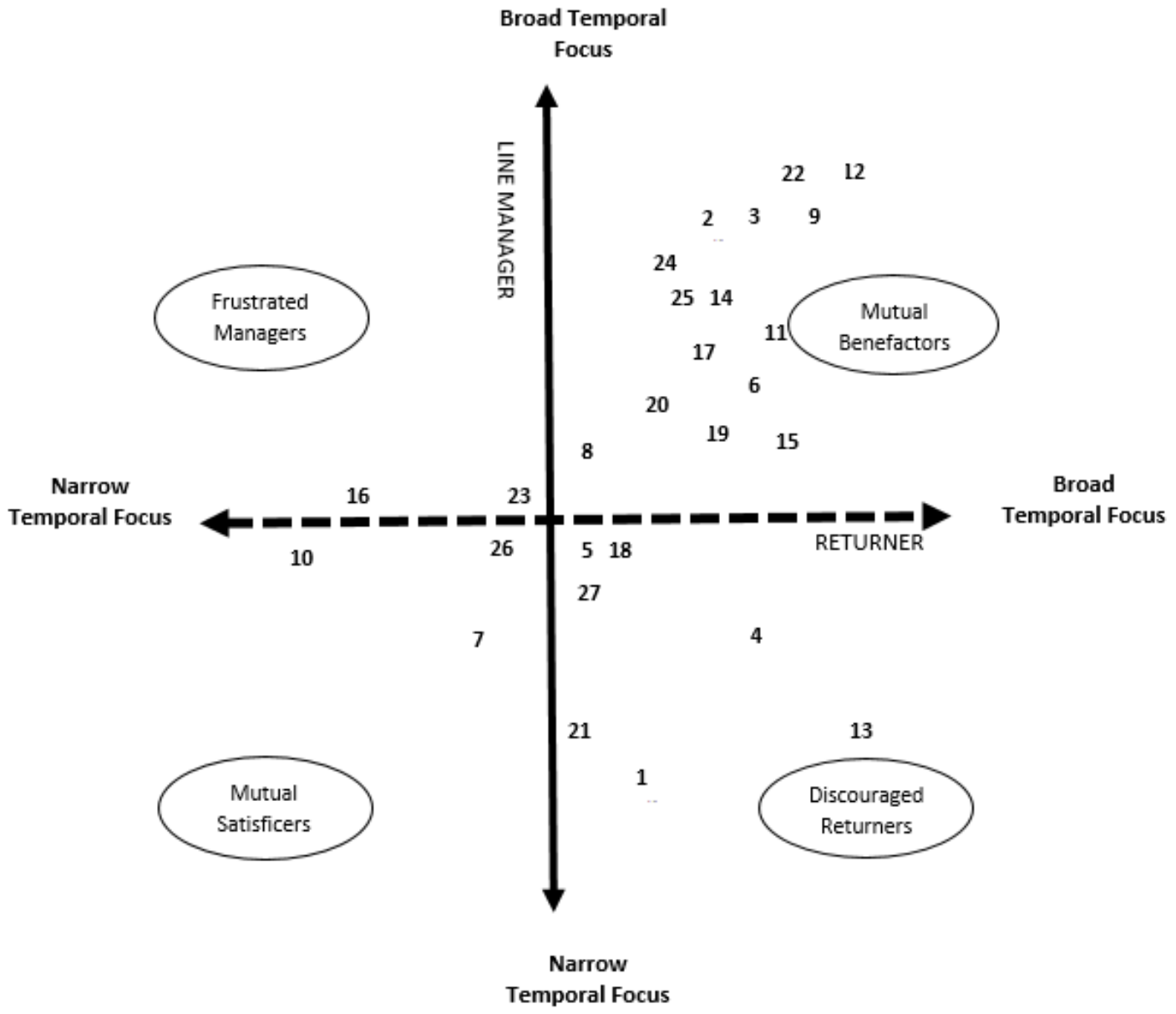

Figure 1. Dyadic Mapping and Labels according to Temporal Focus (In) Congruence

Table 1. Supporting evidence on how temporal focus permits or overcomes motherhood bias

\begin{tabular}{|c|c|c|}
\hline \multicolumn{3}{|c|}{ Temporal Focus basis to Motherhood Bias } \\
\hline & Returner Quote & Manager Quote \\
\hline \multirow[t]{2}{*}{$\begin{array}{l}\text { Narrow Focus } \\
\text { triggers } \\
\text { Motherhood } \\
\text { Bias }\end{array}$} & $\begin{array}{l}\text {... when you come back after your } \\
\text { first, people have some sort of } \\
\text { unconscious bias that you'll probably } \\
\text { go off and have a second at some } \\
\text { point. I think that perception or } \\
\text { peoples' opinion changes of you. I } \\
\text { think they're less likely to get you } \\
\text { involved in long term stuff... I } \\
\text { suppose you kind of feel a little bit } \\
\text { hard done by, which I suppose is for } \\
\text { me to get over; that you've put in so } \\
\text { much time (Org 1R) }\end{array}$ & $\begin{array}{l}\text { I would see that coming all the way } \\
\text { through to director is do-able for most } \\
\text { working mums, the difficulty I think in } \\
\text { our organization is that the jump } \\
\text { between director to partner at the } \\
\text { moment requires such a heavy } \\
\text { investment in your career (Org } 1 \mathrm{M} \text { ) }\end{array}$ \\
\hline & $\begin{array}{l}\text { So, they completely shut the door } \\
\text { [on promotion], there was no budget }\end{array}$ & $\begin{array}{l}\text { I think their priorities change, } \\
\text { ambition, I'm not } 100 \% \text { sure. I think }\end{array}$ \\
\hline
\end{tabular}


for this year... but it didn't really meet my expectation. Sometimes I look at other successful women, and I just wonder how they manage after maternity leave to go back to work and get a promotion (Org 13R)

because priorities might change then ambition kind of follows suit as well, so where you might have somebody who might have deferred their pregnancy because they wanted to career advance ... when they return, and I genuinely have seen women at both sides of the spectrum, where they would have been career go getters destined for whatever they wanted to be but when they returned this had waned quite a bit and it would have taken them quite a while to get re-energised (Org 13M)

Broad Focus overcomes Motherhood Bias
I didn't expect it when I did go for the internal promotion and I was successful, I didn't expect them to actually give me the role before I went on maternity leave, I would have expected them to say 'when you are back from maternity leave you will start your new role' and that's what I fully expected so I did think they were quite generous to give it to me before I went...So, I was very grateful, very grateful (Org 11R)

[Employer] never disappointed me in my career. And maternity was absolutely not a blocker at all for me to come to a new role and move... So, from the very beginning of $\mathrm{my}$ pregnancy I actually sat down you know with my HRBP who proactively approached me and said, 'let's start planning about what happens after you come back from maternity leave' (Org 9R)
I think it's the culture of people can go for promotion when they're eight months pregnant and due to go on maternity leave and no one would question that (Org 11M) we do a lot of education on unconscious bias. I think the natural blocker or competitive disadvantage that women have is when it comes to having families it will be the mother that takes most of the time off and not the father so again some of the things we do is to allow flexible and when she was going on maternity leave I was staying in contact trying to understand what were her personal preferences, where does she want to move to. First of all, I was just trying to find what was the right role for her and was she interested in returning back to Dublin because I sit on the Dublin site leadership team so we are always trying to attract the best so we are always interested in hiring great leaders and managers from our offices all around the world, so, again I did a lot of engaging with $X$ while she was on her maternity leave and she did her interviews on her leave (Org 9M) 
Table 2. Supporting Evidence for Dyadic Temporal Incongruence

\begin{tabular}{|c|c|c|c|}
\hline Dyad Label & Cases & Returner Temporal Focus & Manager Temporal Focus \\
\hline $\begin{array}{l}\text { Discouraged } \\
\text { Returner }\end{array}$ & $\begin{array}{l}1,4 \\
5,13 \\
18 \\
21,27\end{array}$ & $\begin{array}{l}\text { The reality is I'm well able to do } \\
\text { my job in the time, my job } \\
\text { hasn't suffered at all, however, } \\
\text { the perception probably has, } \\
\text { because I'm not sitting there in } \\
\text { the evenings at six o'clock... I've } \\
\text { been on the phone several } \\
\text { times and I've been on emails } \\
\text { later, it's no issue, but } \\
\text { sometimes it's different from } \\
\text { being physically there (Org 21R) }\end{array}$ & $\begin{array}{l}\text { I would say there is certainly a } \\
\text { perception that you aren't here, you } \\
\text { know, you're off on your maternity } \\
\text { leave, you're not allowed think in } \\
\text { those terms but I think people do } \\
\text { think in those terms (Org } 21 \mathrm{M} \text { ) }\end{array}$ \\
\hline $\begin{array}{l}\text { Frustrated } \\
\text { Manager }\end{array}$ & 16,23 & $\begin{array}{l}\text { say a promotion for argument's } \\
\text { sake, I probably don't feel I } \\
\text { could do that job in four days... } \\
\text { But I feel, I probably would be } \\
\text { slower to go for stuff for the } \\
\text { fact that I am only working for } \\
\text { four days (Org 16R) }\end{array}$ & $\begin{array}{l}\text { A lot of it is down to the individual as } \\
\text { well in terms of their own type of } \\
\text { behaviors around performance and, } \\
\text { you know, what they want to } \\
\text { achieve... "Oh well, I am not here that } \\
\text { day so I will have to wait until next } \\
\text { week" ... Like, actually that can be } \\
\text { frustrating... we're getting into the } \\
\text { realm of those behaviors not being } \\
\text { transferable to a more senior position } \\
\text { (Org } 16 \mathrm{M} \text { ) }\end{array}$ \\
\hline $\begin{array}{l}\text { Mutual } \\
\text { Benefactors }\end{array}$ & $\begin{array}{l}2,3 \\
6,8 \\
9,11 \\
12 \\
14 \\
17 \\
19 \\
20, \\
22 \\
24, \\
25\end{array}$ & $\begin{array}{l}\text { I said it before I left and while I } \\
\text { was speaking to them when I } \\
\text { was off I still want to progress in } \\
\text { here, I still want to do well... I } \\
\text { don't see why if you have a } \\
\text { baby why that should affect you } \\
\text { wanting to progress, that's me } \\
\text { personally. (Org 14R) }\end{array}$ & $\begin{array}{l}\text { I only have } X \text { to base it on, she's come } \\
\text { back, she's hit the ground running, } \\
\text { she's coming in, she is very, very } \\
\text { capable when she is here she is here, } \\
\text { so she is not thinking about being } \\
\text { somewhere else...but at the same } \\
\text { time I believe her priority is her baby } \\
\text { which is what it should be but we all } \\
\text { have a job to do and she comes and } \\
\text { she is a valuable member of the team } \\
\text { (Org } 14 \mathrm{M} \text { ) }\end{array}$ \\
\hline $\begin{array}{l}\text { Mutual } \\
\text { Satisficers }\end{array}$ & $\begin{array}{l}7,10 \\
26\end{array}$ & $\begin{array}{l}\text { I was very much career focused. } \\
\text { Now I still am but I am kind of } \\
\text { on a pause button at the } \\
\text { moment. Because you re-adjust } \\
\text { your priorities and right now } \\
\text { family is the priority and I } \\
\text { suppose you only have a } \\
\text { window as the female to do this } \\
\text { so you do adjust. (Org 10R) }\end{array}$ & $\begin{array}{l}\text { Certainly their focus and their } \\
\text { emphasis will be very different. And } \\
\text { again, I keep putting in the word } \\
\text { naturally, that's natural but if it comes } \\
\text { to at ten o'clock at night answering an } \\
\text { email or getting to bed because baby } \\
\text { will be up during the night then we } \\
\text { are going to go to bed because we } \\
\text { need to be up naturally. So, versus a } \\
\text { person who doesn't have that } \\
\text { commitment... (Org 10M) }\end{array}$ \\
\hline
\end{tabular}


Table 3. Supporting Evidence for Returner Career Outcomes

\begin{tabular}{|c|c|c|c|}
\hline Dyad Label & $\begin{array}{l}\text { Case } \\
\mathrm{s}\end{array}$ & Returner Quotes & Manager Quotes \\
\hline $\begin{array}{l}\text { Discouraged } \\
\text { Returner }\end{array}$ & $\begin{array}{l}1,4 \\
5 \\
13 \\
18 \\
21 \\
27\end{array}$ & $\begin{array}{l}\text { [role erosion] I also didn't get all my } \\
\text { clients back. Before I went, I was } \\
\text { promised: "you will get all your clients } \\
\text { back", so that was part of the reason I } \\
\text { came back. I thought the sooner I come } \\
\text { back and get my clients back the better, } \\
\text { but when I came back that didn't happen } \\
\text { (Org 1R) }\end{array}$ & $\begin{array}{l}\text { [returner's lower performance] [Asked } \\
\text { whether he had re-evaluated someone } \\
\text { post maternity leave] Yes, but not } \\
\text { because of the maternity leave but } \\
\text { because of the performance on return. } \\
\text { I think, the way this place is, it's easy to } \\
\text { spot when people are just deciding: } \\
\text { "Well, ah, I'm not going to work as hard } \\
\text { as I did" (Org 1M) }\end{array}$ \\
\hline $\begin{array}{l}\text { Frustrated } \\
\text { Manager }\end{array}$ & $\begin{array}{l}16, \\
23\end{array}$ & $\begin{array}{l}\text { [opting to slow down] There's nearly } \\
\text { always jobs of some description being } \\
\text { advertised but... I'd probably, I'd be } \\
\text { slower to go for them because I } \\
\text { suppose the level I am at now, if I am to } \\
\text { go for, we'll say a promotion, I probably } \\
\text { don't feel I could do that job in four } \\
\text { days... I don't particularly want } \\
\text { promotion at the moment. I am very } \\
\text { happy (Org 16R) }\end{array}$ & $\begin{array}{l}\text { [loss of momentum] not to separate } \\
\text { men versus women, but if an } \\
\text { individual needed to step out, } \\
\text { obviously, you know, things would } \\
\text { keep moving and they would be on } \\
\text { that trajectory and a person will miss } \\
\text { out, you know, and that's natural... I } \\
\text { think it would be naïve to say, "Oh, } \\
\text { they don't miss out" (Org 16M) }\end{array}$ \\
\hline $\begin{array}{l}\text { Mutual } \\
\text { Benefactors }\end{array}$ & $\begin{array}{l}2,3 \\
6,8 \\
9, \\
11 \\
12 \\
14, \\
17 \\
19 \\
20 \\
22 \\
24 \\
25\end{array}$ & $\begin{array}{l}\text { [fresh perspective] I think I'm trying to } \\
\text { fall back in love with [my job] again. I } \\
\text { needed that step out to get a fresh } \\
\text { perspective to go back and say, 'what } \\
\text { level do I want to perform at again? And } \\
\text { how do I be even more efficient, more } \\
\text { productive, and progress in my career } \\
\text { going back?' I do feel that the person } \\
\text { I'm coming back as is different to the } \\
\text { person I was when I left, there's that re- } \\
\text { branding to be done. I'm so much more } \\
\text { critical as to where I spend my time... } \\
\text { because every moment matters, but I'm } \\
\text { more ruthless in terms of trying to } \\
\text { prioritise what my day entails (Org 6R) }\end{array}$ & $\begin{array}{l}\text { [supporting performance] when they } \\
\text { come back, there's a period of time } \\
\text { where they need additional support to } \\
\text { get back up to speed on things. } \\
\text { There's a whole bunch of context that } \\
\text { they won't have from the last six, } \\
\text { seven, or up to twelve months in } \\
\text { some cases, that we can't assume } \\
\text { they have... I try to invest a lot of time } \\
\text { in the context piece... it is too easy to } \\
\text { assume that they have all the } \\
\text { information they need, at that time, to } \\
\text { be effective in their role. So, I try to } \\
\text { invest extra time in filling them in } \\
\text { where things change rapidly (Org } 6 \mathrm{M} \text { ) }\end{array}$ \\
\hline $\begin{array}{l}\text { Mutual } \\
\text { Satisficers }\end{array}$ & $\begin{array}{l}7, \\
10 \\
26\end{array}$ & $\begin{array}{l}\text { [capacity to maintain input] you're } \\
\text { wanting to do a good job, do it well, to } \\
\text { do it with heart and commitment and to } \\
\text { get the right thing done, but there's } \\
\text { also weighing that up against, I am only } \\
\text { here for a certain number of hours, and } \\
\text { not that things don't get done but just } \\
\text { the list gets longer... So the } \\
\text { opportunities are still there but there's } \\
\text { only so much that you can do... I feel I } \\
\text { do it less well than I did before you } \\
\text { know, time, I still think it's a five-day } \\
\text { week job, but I am rarely working five } \\
\text { days (Org 26R) }\end{array}$ & $\begin{array}{l}\text { [acknowledge changed priorities] The } \\
\text { first risk you have where someone is } \\
\text { going on leave is that they may not } \\
\text { come back because it's an important } \\
\text { life change for a person and no matter } \\
\text { how much their career has meant to } \\
\text { them to this point, it may not mean } \\
\text { that much to them after...we are } \\
\text { never going to be truly inclusive unless } \\
\text { we can address the fact that much of } \\
\text { the population can't offer themselves } \\
9 \text { to } 5 \text {. That's the truth. I don't care } \\
\text { how talented they are (Org } 26 \mathrm{M} \text { ) }\end{array}$ \\
\hline
\end{tabular}


Table 4. Supporting Evidence for Relational Outcomes

\begin{tabular}{|c|c|c|c|}
\hline Dyad Label & Cases & Returner Quote & Manager Quote \\
\hline $\begin{array}{l}\text { Discouraged } \\
\text { Returner }\end{array}$ & $\begin{array}{l}1,4 \\
5,13 \\
18 \\
21,27\end{array}$ & $\begin{array}{l}\text { [ambivalence] [through tears] } \\
\text { When I came back, I brought it up } \\
\text { with him that my plan was to } \\
\text { start early and I think he had a } \\
\text { kind of a look, but he said it was } \\
\text { fine...It was business as usual, I } \\
\text { didn't feel unsupported. [When } \\
\text { asked was there any type of } \\
\text { support provided], he's a nice } \\
\text { man but it wouldn't have crossed } \\
\text { his mind. (Org 4R) }\end{array}$ & $\begin{array}{l}\text { [self-prioritization] If [returner] came } \\
\text { to me and asked me could she do that } \\
\text { as long as I was sure that the work } \\
\text { would be done I would be open to it. } \\
\text { Has she asked me if she could do that? } \\
\text { No. Will I go to her and offer that to } \\
\text { her? No. Come to me and ask me } \\
\text { because I'm, she's at such a level...and } \\
\text { I'm very much being measured against } \\
\text { her output (Org 4M) }\end{array}$ \\
\hline $\begin{array}{l}\text { Frustrated } \\
\text { Manager }\end{array}$ & 16,23 & $\begin{array}{l}\text { [lack of psych safety] I'd hate to } \\
\text { think he was having that } \\
\text { conversation with me because } \\
\text { you couldn't cope or you weren't } \\
\text { fit for it or you've lost interest in } \\
\text { your job and all you want to do is } \\
\text { run out the door... I think it has to } \\
\text { be in a more neutral, a safer } \\
\text { environment, where you can } \\
\text { really say, 'well actually I'm } \\
\text { finding it really difficult... just to } \\
\text { have that chat. Someone to say, } \\
\text { 'are you okay? (Org 23R) }\end{array}$ & $\begin{array}{l}\text { [lack of returner benevolence] } \\
\text { sometimes I'd be pushing back a little } \\
\text { bit like that and saying, 'well that's } \\
\text { fine it's a completely personal decision } \\
\text { we all make these personal decisions } \\
\text { for work-life balance', and you can see } \\
\text { lots of women more than men making } \\
\text { these decisions but for somebody who } \\
\text { does actually want to be a manager } \\
\text { okay you've made a choice but you } \\
\text { need to understand the consequences } \\
\text { of that choice... if they have aspiration } \\
\text { they need to understand how they } \\
\text { actually get that aspiration. (Org } 23 \mathrm{M} \text { ) }\end{array}$ \\
\hline $\begin{array}{l}\text { Mutual } \\
\text { Benefactors }\end{array}$ & $\begin{array}{l}2,3 \\
6,8 \\
9,11 \\
12, \\
14, \\
17 \\
19, \\
20, \\
22, \\
24,25\end{array}$ & $\begin{array}{l}\text { [manager benevolence] when I } \\
\text { was coming back, I met with my } \\
\text { line manager and I put in the } \\
\text { three-day request again, and he } \\
\text { just said, "That's fine, whatever } \\
\text { you want" and just the day a } \\
\text { week, like, I would just work from } \\
\text { home. I didn't even have to ask, } \\
\text { you know. It's just that I have } \\
\text { been really surprised (Org 24R) }\end{array}$ & $\begin{array}{l}\text { [relational investment] You'll go the } \\
\text { extra mile for her because you really } \\
\text { want to retain her and you really } \\
\text { respect her and she is damn good at } \\
\text { her job and you will do whatever you } \\
\text { need to do to make sure she's } \\
\text { comfortable (Org 24M) }\end{array}$ \\
\hline $\begin{array}{l}\text { Mutual } \\
\text { Satisficers }\end{array}$ & $\begin{array}{l}7,10 \\
26\end{array}$ & $\begin{array}{l}\text { [manager benevolence; felt trust] } \\
\text { [My manager] has been absolutely } \\
\text { great. He's quite aware that } \\
\text { people have moved into a non- } \\
\text { client-facing role for family or } \\
\text { lifestyle reasons, he would be } \\
\text { quite conscious of things that } \\
\text { interfere with your time. So, for } \\
\text { example he wouldn't suggest a } \\
\text { workshop in the evening. He gives } \\
\text { you a lot of autonomy as well and } \\
\text { trusts your judgement. It makes } \\
\text { all the difference (Org 7R) }\end{array}$ & $\begin{array}{l}\text { [acceptance] [returner] that you'll be } \\
\text { meeting with, was a transactional } \\
\text { lawyer for most of her career and an } \\
\text { exceptionally good transactional } \\
\text { lawyer. She's very smart, very clever, } \\
\text { gives great client care, she's a great } \\
\text { colleague, and she has chosen to } \\
\text { move to a different role with us, which } \\
\text { we call a professional support lawyer, } \\
\text { the role would give her greater } \\
\text { predictability in terms of starting and } \\
\text { finishing times (Org 7M) }\end{array}$ \\
\hline
\end{tabular}

